\title{
In vitro slow growth storage of Senecio macrophyllus shoots
}

\author{
Alina Trejgell $^{1} \cdot$ Monika Kamińska $^{1} \cdot$ Andrzej Tretyn $^{1}$
}

Received: 27 March 2015/Revised: 21 July 2015/Accepted: 5 October 2015/Published online: 17 October 2015

(C) The Author(s) 2015. This article is published with open access at Springerlink.com

\begin{abstract}
Advances in biotechnology, especially in the field of in vitro culture techniques, led to the development of procedures that can be used as an excellent tool in plant conservation. The present study describes in vitro conservation of Senecio macrophyllus by slow-growth storage. Various sugar treatments, concentration of abscisic acid (ABA), light intensity and type of containers were tested. Viability and proliferation rate of shoots were evaluated 4 weeks after regrowth. The results obtained showed that polycarbonate boxes were a better type of containers for storage of S. macrophyllus shoots than glass vessels. Light negatively affected culture viability, multiplication rate and rooting response. In the case of Senecio macrophyllus the addition of ABA to storage medium stimulated survival and higher proliferation of shoots during regrowth in optimal conditions in comparison to shoots stored on medium without ABA. Shoots of S. macrophyllus were effectively stored for 6 months. All rooted shoots survived adaptation to field conditions and were able to flower in the second year after acclimatization.
\end{abstract}

Keywords In vitro storage - Senecio macrophyllus . Shoot tips $\cdot$ ABA

Communicated by M. Lambardi.

Alina Trejgell

trejgell@umk.pl

1 Chair of Plant Physiology and Biotechnology, Nicolaus Copernicus University, Lwowska 1, 87-100 Toruń, Poland

\section{Introduction}

The latest International Union for Conservation of Nature statistics show that out of over 12,000 plant species, $70 \%$ are threatened, $19 \%$ are critically endangered and 28 species are extinct in the wild. In situ conservation alone may not be enough to rescue some of the rarest plants (Sarasan 2010). Besides the classical forms of protection of endangered species in the past three decades, advances in biotechnology and especially in the field of in vitro culture techniques led to the development of procedures that can be used as an excellent tool in plant protection (Maryam et al. 2014). The most important aspects of this protection are the development of efficient regeneration systems for many endangered species, that is micropropagation, and the protection of the morphogenetic potential of cell cultures, tissue or organs (Rybczyński and Mikuła 2006). Although standard in vitro propagation methods are available, endangered species may have unusual growth requirements and thus may require modified procedures for in vitro culture (Reed et al. 2011).

In vitro cultures used for the micropropagation of plants are an excellent tool to protect endangered species. Clonal propagation techniques need to create culture conditions conducive to intensive growth. Media used for micropropagation are supplemented with growth regulators and trophic ingredients in appropriate proportions and the cultures are carried out in an optimal growth temperature and light intensity. The cultures run in optimal conditions; however, they require passage to fresh medium every few weeks, and the procedure is laborious, costly and fraught with the risk of somaclonal variation and microorganism contamination. In vitro culture may also be used for conservation of plant genetic resources. The development of procedures for slow growth led to maintaining the cloned 
material for a few months to several years (depending on the species) under tissue culture conditions, requiring only infrequent subculturing (Rao 2004). Slow growth of in vitro cultures can be achieved by reducing the osmotic potential of the storage medium, lowering incubation temperature or altering medium composition and photon flux density (Withers and Engelmann 1997). The most important factor in the slow growth culture is temperature reduction, often with a simultaneous decrease in light intensity or even culture in the dark, which limits shoot growth from callus induction and proliferation of the base of the shoots. According to the data this minimizes further growth and the development of plantlets or other explants is already guaranteed by the use of a temperature of $0-10^{\circ}$ C (Orlikowska 1992; Hausman et al. 1994; Reed 2002). Furthermore, by modifying the composition of the medium mainly by reducing the sucrose content and/or minerals, the use of hormonal growth retardants, e.g. abscisic acid (ABA) or osmotic agents such as mannitol and sorbitol, inhibition of cell division can be achieved, which significantly limits the growth of both callus and shoot formation (Lambardi et al. 2006; Moges et al. 2003; Shibli et al. 2006). Moreover, the addition of ABA to the medium, especially in cold conditions, increases tolerance to dehydration of tissues and stimulates their survival (Kobayashi et al. 2008). Post-storage vigour of the explants depends on different storage conditions, which include temperature, lighting conditions, medium composition, time of storage, type of container and plant genotype (Hausman et al. 1994; Kovalchuk et al. 2009).

The aim of the study is to determine the conditions for storage of shoots of Senecio macrophyllus in slow-growing cultures and the survival of cultures, and their proliferation in the first passage at normal temperature after storage at $10{ }^{\circ} \mathrm{C}$ in light or dark, in relation to media used during cold storage. Senecio macrophyllus M. Bieb. (Astreaceae) is an extremely rare species and is listed in the Polish Red Data Book (Zarzycki and Szeląg 2006). Cultures in vitro used for the micropropagation of Senecio could help in its conservation, because its seeds completely lose their ability to sprout after 1 year, making it unfeasible to set up a seed bank.

\section{Materials and methods}

\section{Plant material}

Senecio macrophyllus shoot tips were micropropagated in $300 \mathrm{ml}$ glass jars with $50 \mathrm{ml}$ MS medium with $4.4 \mu \mathrm{M}$ benzyladenine (BA), $0.54 \mu \mathrm{M}$ 1-naphthaleneacetic acid (NAA) and $0.8 \%$ agar. Shoots were cultured in continuous white fluorescent light $\left(80 \mu \mathrm{mol} \mathrm{m} \mathrm{m}^{-2} \mathrm{~s}^{-1}\right)$ at $26 \pm 1{ }^{\circ} \mathrm{C}$ and subcultured on a 4-week cycle prior to storage (Trejgell et al. 2010).

\section{Storage conditions}

In the first experiment, shoot tips isolated from the cluster were stored in $300 \mathrm{ml}$ glass jars and $300 \mathrm{ml}$ polycarbonate magenta boxes with polypropylene cover (both vessels) that contained $50 \mathrm{ml}$ half-strength MS (Murashige and Skoog 1962) medium (1/2MS) supplemented with $2.2 \mu \mathrm{M}$ BA and $0.27 \mu \mathrm{M}$ NAA. Three carbohydrate treatments were tested: $3 \%$ sucrose ( $3 \% \mathrm{sc}$ ), $1.5 \%$ sucrose plus $1.5 \%$ sorbitol $(1.5 \% \mathrm{sc}+\mathrm{sb})$, and $3 \%$ sucrose plus $3 \%$ sorbitol $(3 \%$ $\mathrm{sc}+\mathrm{sb})$. The experiment was conducted in darkness.

In the second experiment, shoot tips were kept in magenta boxes containing $1 / 2 \mathrm{MS}$ with different combinations of carbohydrates, supplemented with $2.2 \mu \mathrm{M}$ BA and $0.27 \mu \mathrm{M}$ NAA and additionally with ABA at a concentration of 3.8 or $9.5 \mu \mathrm{M}$. Shoot tips stored on medium without ABA were the control. The experiment was conducted in darkness or in continuous white fluorescent light $\left(40 \mu \mathrm{mol} \mathrm{m} \mathrm{m}^{-2} \mathrm{~s}^{-1}\right)$.

The $\mathrm{pH}$ of all types of medium was adjusted to 5.8 before autoclaving. The media were sterilized for $20 \mathrm{~min}$ at $120{ }^{\circ} \mathrm{C}$. All stored cultures were incubated in a growth room with reduced temperature $\left(10{ }^{\circ} \mathrm{C}\right)$ for 3,6 or 9 months in darkness.

\section{Data collection}

The shoots were evaluated at 3-month intervals in accordance with the schema procedure reported in Fig. 1. Analysis of the visual rating was conducted directly after transfer to optimal growth conditions. Shoots were rated on the scale from 0 to 5 , based on plant appearance (Reed 1992, modified): 0-dead shoot, all brown, 1-shoot mostly brown, only extreme shoot tip visibly yellow, 2shoot yellow-brown, 3-shoot with etiolated tip, base of

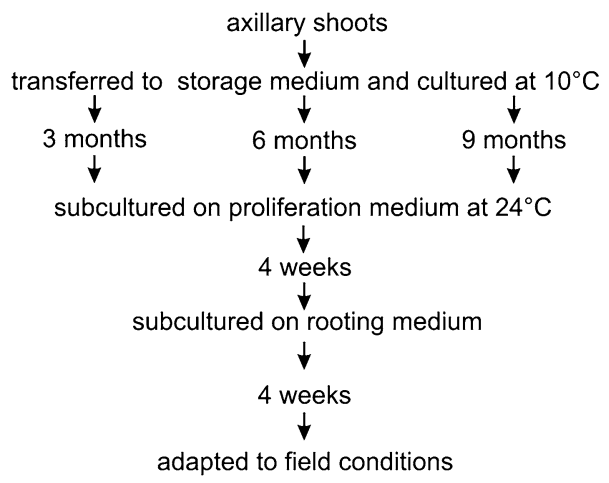

Fig. 1 Schematic procedure of storage and regrowth of $S$. macrophyllus 
stem brown, 4-shoot with etiolation, 5-shoot bright green. Viability and proliferation rate of shoots were evaluated 4 weeks after transfer to optimal growth conditions. Shoots were subcultured on MS medium with fullstrength nutrients, supplemented with $4.4 \mu \mathrm{M}$ BA and 0.54 $\mu \mathrm{M}$ NAA under continuous white fluorescent light $\left(80 \mu \mathrm{mol} \mathrm{m}{ }^{-2} \mathrm{~s}^{-1}\right)$ at $26 \pm 1{ }^{\circ} \mathrm{C}$. The shoots obtained were excised and transferred on rooting medium (MS without auxin). The percentage of rooted shoots and the number of roots per shoot were recorded after 4 weeks of culture. The plantlets were removed from the in vitro cultures, washed gently with sterile water, transferred to plastic pots containing a sterile mixture of vermiculite and sand $(1: 1 \mathrm{v} / \mathrm{v})$, and covered with transparent boxes to maintain humidity (60-70\%). After 8 weeks of acclimatization the survival rates were determined, and then the plantlets were transferred to field conditions. The survival level and the ability to flower were analysed during 2 years.

\section{Data analysis}

In each variant of storage 30 shoots were used (six shoot tips in each magenta/jar). The experiments were conducted twice. Data on regrowth under optimal conditions (multiple rate and percentage of rooted shoots and number of roots per shoot) were obtained for shoots that survived the cold treatment. Data were expressed as mean \pm standard error (SE) and analysed by ANOVA. To examine significant differences among the treatments Tukey's multiple range test at $p<0.05$ was then performed.

\section{Results}

The visual rating of shoot tips was 5 on establishment of culture, decreasing with the duration of storage. Analysis of the visual rating in the first experiment showed that for each of the media the value was higher when shoot tips were stored in magenta boxes compared to plant material stored in glass jars (Table 1; Figs. 2, 3a, b). After 9 months of storage in magenta boxes the visual rating ranged from 1.0 to 1.6. The highest value was recorded for the shoots planted on medium with $3 \%$ sucrose (Table 1 ).

Shoot tips after 3, 6 and 9 months of storage at $10^{\circ} \mathrm{C}$ were transferred to optimal growth conditions. Multiple rates recorded after regrowth following the 3 months of storage in magenta boxes on medium with $4.4 \mathrm{BA}$ were lower compared to results obtained during multiplication of non-stored shoots on a medium of the same composition of growth regulators, but similar to results recorded on a medium containing 2.2 BA and 0.27 NAA (Trejgell et al. 2010). By contrast, the multiple rate for shoots stored in glass jars was about half that and differences were statistically significant (Table 1). Extension of the storage to 9 months significantly reduced the multiple rate. The best responses were observed when shoots were stored on medium with $1.5 \%$ sucrose plus $1.5 \%$ sorbitol: multiple rates were 2.3 (Fig. 3c) and 1.0 after 6 and 9 months, respectively (Fig. 4a). ANOVA indicated significant interaction between the type of container and carbohydrate treatment during shoot multiplication after 6 and 9 months of storage (Table 1). Magenta boxes were a better type of container for storage of S. macrophyllus shoots.

Table 1 Analysis of the interaction between the type of container and sugar treatment during cold storage on the visual rating and during poststorage multiplication of shoots and rooting of $S$. macrophyllus performed by two-way ANOVA

\begin{tabular}{|c|c|c|c|c|c|c|c|c|c|}
\hline \multirow[t]{2}{*}{ Treatments } & \multicolumn{3}{|c|}{ Visual rating } & \multicolumn{3}{|c|}{ Multiple rate } & \multicolumn{3}{|c|}{ Rooting rate } \\
\hline & MS & $F$ & $p$ value & MS & $F$ & $p$ value & MS & $F$ & $p$ value \\
\hline \multicolumn{10}{|l|}{3 months of storage } \\
\hline Type of container (A) & 19.38 & 38.72 & $<0.0001$ & 49.01 & 31.58 & $<0.0001$ & 336.40 & 144.76 & $<0.0001$ \\
\hline Sugar treatment (B) & 13.07 & 26.11 & $<0.0001$ & 0.90 & 0.58 & $0.5625 \mathrm{~ns}$ & 37.64 & 16.20 & $<0.0001$ \\
\hline $\mathrm{A} \times \mathrm{B}$ & 0.88 & 1.76 & $0.1751 \mathrm{~ns}$ & 0.02 & 0.01 & $0.9867 \mathrm{~ns}$ & 4.13 & 1.78 & $0.1751 \mathrm{~ns}$ \\
\hline \multicolumn{10}{|l|}{6 months of storage } \\
\hline Type of container (A) & 38.52 & 86.07 & $<0.0001$ & 22.69 & 17.82 & $<0.0001$ & 14.40 & 11.86 & 0.0009 \\
\hline Sugar treatment (B) & 0.38 & 0.85 & $0.4293 \mathrm{~ns}$ & 16.35 & 12.84 & $<0.0001$ & 16.58 & 13.65 & $<0.0001$ \\
\hline $\mathrm{A} \times \mathrm{B}$ & 9.72 & 21.73 & $<0.0001$ & 9.89 & 7.77 & 0.0006 & 41.20 & 33.93 & $<0.0001$ \\
\hline \multicolumn{10}{|l|}{9 months of storage } \\
\hline Type of container (A) & 34.17 & 98.97 & $<0.0001$ & 22.69 & 17.82 & $<0.0001$ & 0.9 & 4725 & 0.0325 \\
\hline Sugar treatment (B) & 5.36 & 15.52 & $<0.0001$ & 16.35 & 12.84 & $<0.0001$ & 0.3 & 1575 & $0.2131 \mathrm{~ns}$ \\
\hline$A \times B$ & 0.98 & 2.85 & $0.0603 \mathrm{~ns}$ & 9.89 & 7.77 & 0.0006 & 0.3 & 1575 & $0.2131 \mathrm{~ns}$ \\
\hline
\end{tabular}



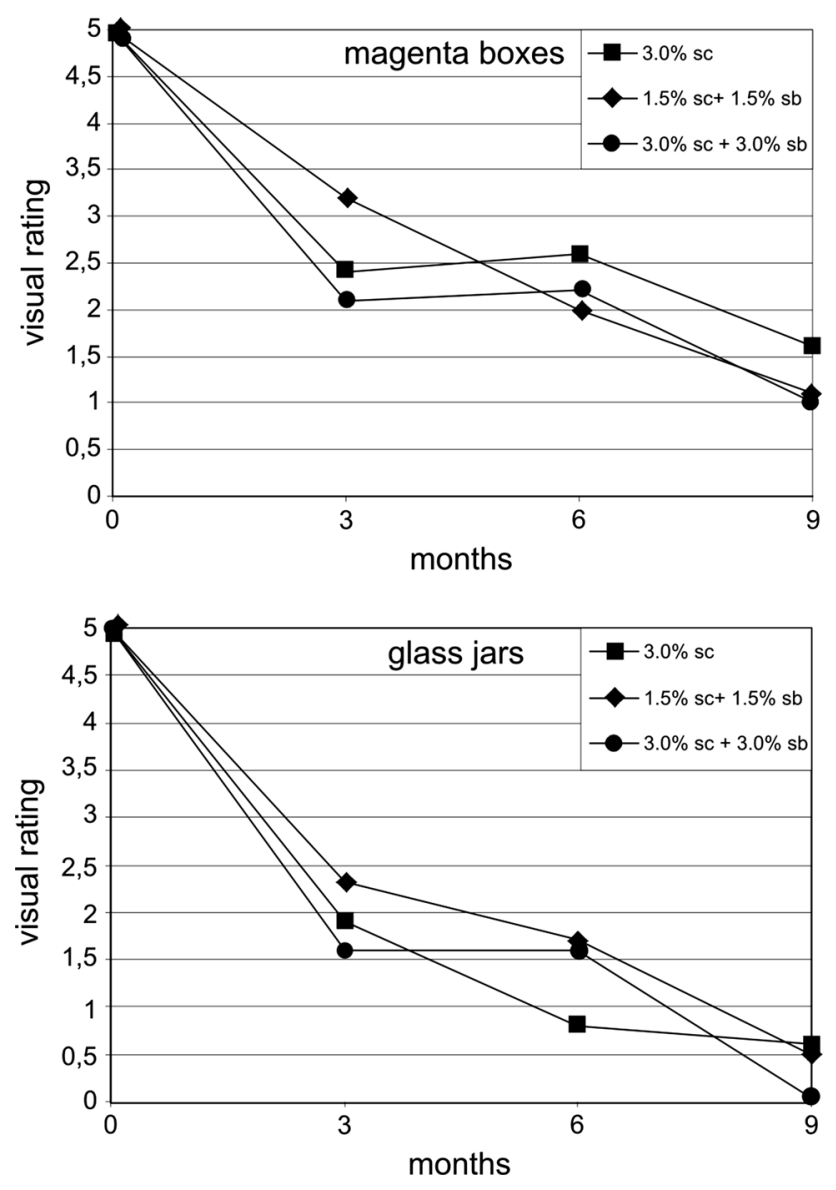

Fig. 2 The effect of carbohydrate treatment during storage in glass jars and magenta boxes on the visual rating of $S$. macrophyllus shoots

The axillary shoots obtained on stored material were rooted. During regrowth following 3 and 6 months of storage on all types of media and in both types of containers, shoots were able to root (Figs. 3d, 4b), but the rooting response of shoots stored for 6 months on all variants of medium and in both types of containers was significantly lower. Root development on the shoots obtained following 9 months of storage was observed only when magenta boxes were used for storage on medium with $1.5 \% \mathrm{sc}+\mathrm{sb}$ and $3 \% \mathrm{sc}+\mathrm{sb}$, but the percentage of rooted shoots did not exceed $20 \%$ and the number of roots per shoot was 0.4 and 0.2 , respectively (Fig. 4b, c). The shoots stored on medium with $3 \%$ sucrose in magenta boxes and in glass jars after regrowth were not able to root (Fig. 4b, c). The type of container used for storage and the combination of sugar used in the culture medium had a significant effect on the rooting of shoots, but there was no correlation between these treatments (Table 1).

Rooted shoots $(100 \%)$ adapted to ex vitro conditions (Fig. 3e) and all of them were able to flower in the second year after transfer into the field (Fig. 3f).

In the second part of the study the effect of light on the survival of apical growth was investigated. Analysis of the visual rating showed that the light has a negative effect on the storage of $S$. macrophyllus shoots. During the first 3 months of storage the greatest changes were recorded in the morphology of the material stored on the medium with $3 \%$ sucrose and $1.5 \%$ sucrose with sorbitol and the visual rating was not higher than 1 , and in the following months of storage it was $0.6-0.3$ (Fig. 5). After 3 months of storage on the medium with $3 \%$ sucrose and $3 \%$ sorbitol chlorosis lamina and necrotic changes to leaves on stored shoots were observed and the visual rating was 1.6 , which decreased during subsequent storage to a value of 0.5 after 9 months of storage. Storing the shoot in the dark on analogous media did not cause such destructive changes, and the value of the visual rating after 6 months of storage was greater than 2. The addition of $\mathrm{ABA}$ to the medium favoured the shoot stored both in the dark and the light. The highest visual rating (2.7) was reported for the shoot stored in the dark on medium with $1.5 \%$ sucrose and $1.5 \%$ sorbitol supplemented with ABA at a concentration of 3.8 and $9.5 \mu \mathrm{M}$ (Fig. 5). Analysis of the interaction of light conditions and medium on the visual rating after cold storage showed that differences were statistically significant (Table 2).

After transfer to the optimal conditions for the proliferation of shoots, multiple rates were recorded and the highest efficiency of multiplication of shoots (3.7 per explant) was shown by shoots stored for 3 months in darkness on medium with $1.5 \% \mathrm{sc}+\mathrm{sb}$ with the addition of $3.8 \mu \mathrm{M}$ ABA (Fig. 6a). In comparison after 6 and 9 months of storage shoots showed significantly higher rates of proliferation for shoots stored on medium with $3 \%$ sc and $1.5 \% \mathrm{sc}+\mathrm{sb}$ with $\mathrm{ABA}$ regardless of the concentrations used and on medium with $1.5 \% \mathrm{sc}+\mathrm{sb}$ without the addition of ABA. The number of shoots per explant oscillated between 2.2 and 2.6 after 6 months of storage, and after 9 months was in the range 1.0-1.3 (Fig. 6a).

When the shoots were stored in light higher multiple rates for shoots stored for 3 months were recorded on the medium $1.5 \% \mathrm{sc}+\mathrm{sb}$ and $3 \% \mathrm{sc}+\mathrm{sb}$ with the addition of ABA, regardless of the concentration used, whereas after 6 months only on medium with $3 \% \mathrm{sc}+\mathrm{sb}$ and $3.8 \mu \mathrm{M}$ ABA (Fig. 6a). After the extension of storage to 9 months only a few shoots were viable, and their proliferation was inhibited. Light conditions used for storage and the type of culture medium and correlation between these treatments had a significant effect on the multiplication rate (Table 2).

The shoots obtained were able to root, but the extension of storage time inhibited this process. This was particularly visible when the shoots developed from material stored in light for 6 and 9 months. Only in the case of shoots propagated from the material stored on the medium with $3 \%$ sucrose and $3 \%$ sorbitol and $1.5 \%$ sucrose and $1.5 \%$ 

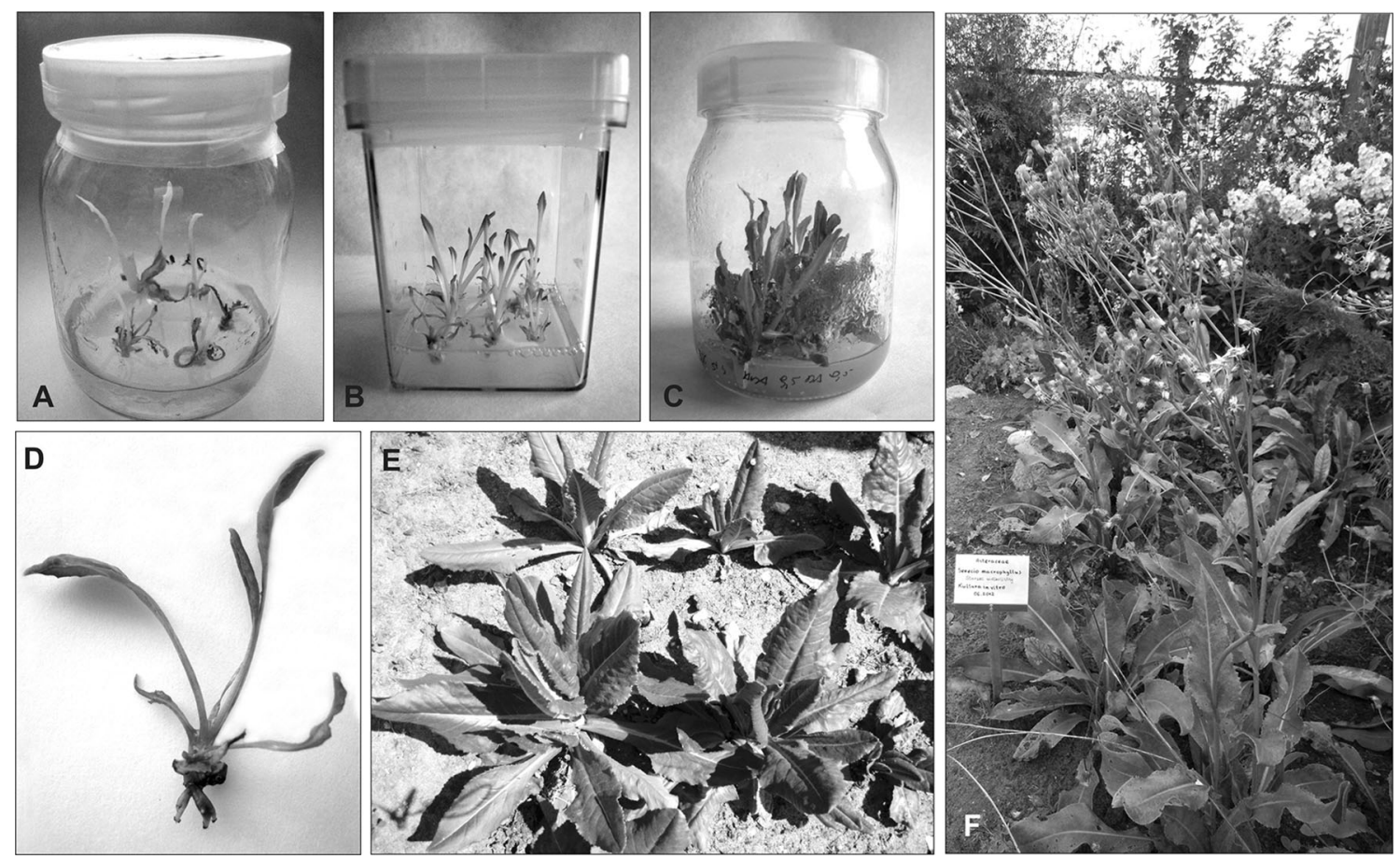

Fig. 3 Storage in vitro of $S$. macrophyllus shoots during 3 months in a glass jar (a) and in a magenta box (b) on medium with $1.5 \%$ sucrose and $1.5 \%$ sorbitol, $\mathbf{c}$ regrowth of shoots on medium with BA $1.0 \mathrm{mg} / \mathrm{L}^{-1}$ and NAA $0.1 \mathrm{mg} / \mathrm{L}^{-1}$ after 6 months of storage in a

sorbitol without the addition of $\mathrm{ABA}$, light conditions did not inhibit rooting (Fig. 6b, c). The addition of ABA to the medium during storage in most variants led to a reduction in both the percentage of rooted shoots as well as the number of roots on the shoot (Fig. 6b, c). Light conditions and the type the culture medium for a duration of 3 and 6 months of storage, as well as the correlation between these treatments had a significant effect on the rooting rate. In contrast, after 9 months of storage significant differences in the rooting rate were observed only on shoots stored in different light conditions (Table 2). Developed roots were short and fairly brittle. All rooted shoots acclimatized to ex vitro conditions, $100 \%$ of plantlets survived transfer to field conditions. Plants developed normally and were able to flower.

\section{Discussion}

Long-term in vitro storage has been successfully improved by applying different treatments, of which reduction of temperature seems to be one of the most important. Plant growth during storage can be suppressed by lowering the temperature, but the optimal storage-temperature depends on species. Typically, a range of $1-10{ }^{\circ} \mathrm{C}$ will be appropriate for temperate species. However, many species magenta box, $\mathbf{d}$ rooted shoot on medium without plant regulators, e plantlets adapted to field conditions, $\mathbf{f}$ flowered plants 2 years after acclimatization

growing well in this climate zone are chill-sensitive and somewhat higher temperatures of $6-12{ }^{\circ} \mathrm{C}$ are used for them. Better results of storage were achieved at a temperature of $8{ }^{\circ} \mathrm{C}$ for Castanea sativa (Capuana and Di Lonardo 2013), but for Beta vulgaris, Solanum sp and Vitis rupesttris a temperature of $9-12{ }^{\circ} \mathrm{C}$ was used (Grout 1995). During storage of the shoot tips of S. macrophyllus a temperature of $10{ }^{\circ} \mathrm{C}$ was applied. This temperature was also the best during storage of the axillary buds of Hosta tokudama (Gollagunta et al. 2005), Podophyllum peltatum (Lata et al. 2010) and Saintpaulia ionantha (Moges et al. 2003).

Different types of containers can have an impact on the condition and survival of plant material stored in vitro. In our study, we tested two types of containers, magenta boxes and glass jars. The results obtained showed that the polycarbonate boxes were a better type of container for storage of S. macrophyllus shoots than glass vessels. In our study we used vessels with covers of the same material, therefore the differences in storage could be affected by the material from which vessels were made. Glass conducts heat better than polycarbonate, so perhaps plant material in the jars was more chilled than the material stored in Magenta boxes. Polycarbonate magenta boxes were also successfully used for cold storage of Solanum tuberosum, Prunus virginiana (Pruski et al. 2000) and for Pistacia 

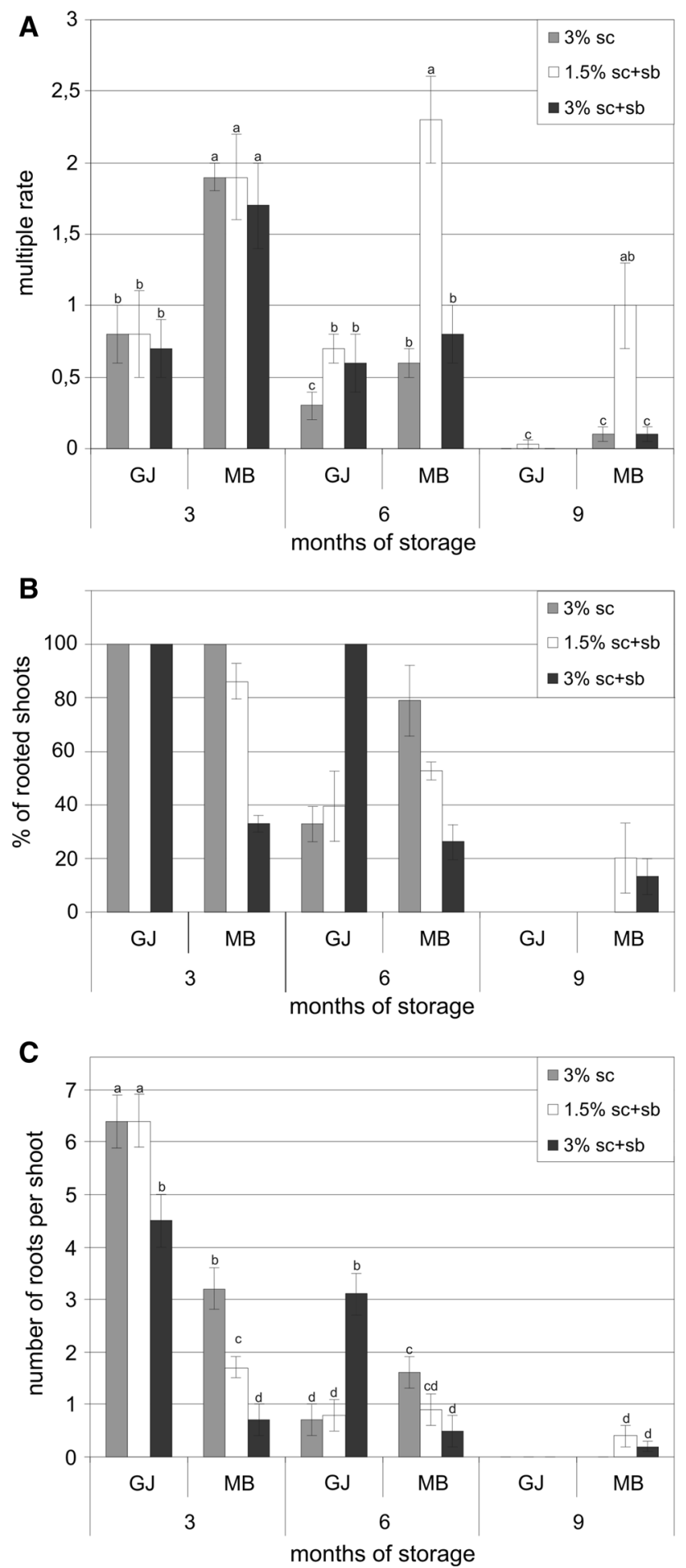

Fig. 4 The effect of carbohydrate treatment and the type of container on multiple shoots (a), \% rooting of shoots (b) and number of roots per shoot (c) of $S$. macrophyllus after storage at $10{ }^{\circ} \mathrm{C}$ (GJ glass jars; $M B$ magenta boxes)

lentiscus (Koç et al. 2014). Similar results were obtained by Kovalchuk et al. (2009) for two varieties of apple, where shoots stored in semi-permeable plastic bags
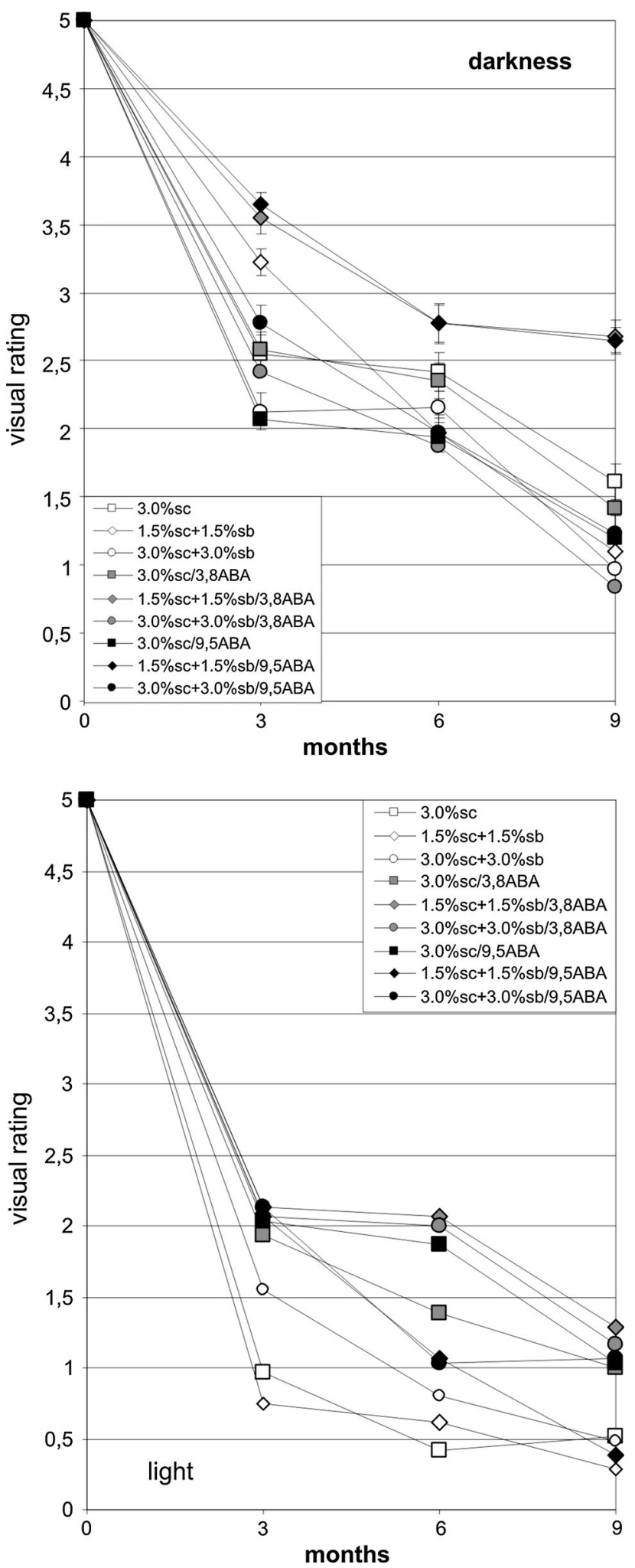

Fig. 5 The effect of carbohydrate treatment during storage in darkness and light conditions on the visual rating of $S$. macrophyllus shoots 
Table 2 Analysis of the interaction of light conditions and medium during cold storage on the visual rating and during post-storage multiplication of shoots and rooting of $S$. macrophyllus performed by two-way ANOVA

\begin{tabular}{|c|c|c|c|c|c|c|c|c|c|}
\hline \multirow[t]{2}{*}{ Source of variation } & \multicolumn{3}{|c|}{ Visual rating } & \multicolumn{3}{|c|}{ Multiplication rate } & \multicolumn{3}{|c|}{ Rooting rate } \\
\hline & MS & $F$ & $p$ value & MS & $F$ & $p$ value & MS & $F$ & $p$ value \\
\hline \multicolumn{10}{|l|}{3 months of storage } \\
\hline Light conditions (A) & 154.903 & 262.723 & $<0.0001$ & 67.377 & 76.091 & $<0.0001$ & 23.115 & 15.961 & $<0.0001$ \\
\hline Medium (B) & 10.187 & 17.278 & $<0.0001$ & 17.429 & 19.683 & $<0.0001$ & 17.320 & 11.960 & $<0.0001$ \\
\hline $\mathrm{A} \times \mathrm{B}$ & 8.758 & 14.854 & $<0.0001$ & 7.674 & 8.666 & $<0.0001$ & 23.465 & 16.203 & $<0.0001$ \\
\hline \multicolumn{10}{|l|}{6 months of storage } \\
\hline Light conditions (A) & 133.565 & 250.658 & $<0.0001$ & 53.777 & 37.519 & $<0.0001$ & 8.533 & 9.339 & 0.0025 \\
\hline Medium (B) & 8.012 & 15.036 & $<0.0001$ & 15.035 & 10.489 & $<0.0001$ & 8.548 & 9.355 & $<0.0001$ \\
\hline $\mathrm{A} \times \mathrm{B}$ & 8.367 & 15.702 & $<0.0001$ & 10.266 & 7.162 & $<0.0001$ & 8.567 & 9.375 & $<0.0001$ \\
\hline \multicolumn{10}{|l|}{9 months of storage } \\
\hline Light conditions (A) & 71.685 & 179.587 & $<0.0001$ & 70.840 & 214.249 & $<0.0001$ & 2.7 & 15.997 & $<0.0001$ \\
\hline Medium (B) & 9.698 & 24.295 & $<0.0001$ & 3.828 & 11.578 & $<0.0001$ & 0.192 & 1.135 & $0.3397 \mathrm{~ns}$ \\
\hline $\mathrm{A} \times \mathrm{B}$ & 9.334 & 23.383 & $<0.0001$ & 3.434 & 10.386 & $<0.0001$ & 0.192 & 1.135 & $0.3397 \mathrm{~ns}$ \\
\hline
\end{tabular}

remained in good condition for 9 months; however, the use of glass vessels allowed storage to be extended for up to 18 months.

Medium composition also influences plant survival and growth during storage. In our study we used half-strength MS medium and standard amounts of sucrose, with or without sorbitol at the same concentration (3\%) or sucrose reduced to half of the quantity with the addition of sorbitol (1.5\%), supplemented with $2.2 \mu \mathrm{M}$ BA and $0.27 \mu \mathrm{M}$ NAA. Reducing the concentration of MS nutrients gave good results during the storage of Lilium longiflorum and $L$. henryi (Bonnier and Van Tuyl 1997). In contrast, during storage of $S$. macrophyllus shoots, reducing the concentration of MS nutrients, growth regulators and the addition of sorbitol to the medium did not limit the necrotic lesions and slightly inhibited shoot growth during storage. A negative correlation was found between strong growth during storage and viability and regrowth after storage, because a significant reduction in regrowth was observed following storage, in comparison to shoots propagated without cold storage where the rate was more than 8 shoots per explant (Trejgell et al. 2010). However, after 6 and 9 months of storage the replacement of $3 \%$ sucrose in the medium on a mixture of $1.5 \%$ sucrose and $1.5 \%$ sorbitol resulted in the highest rate of multiplication among all treatments. Lower rates of proliferation after storage of shoots on medium with a reduced content of sucrose may be due to reduced carbohydrate reserves in the tissues and may lead to a reduction in the potential for regeneration. The addition of mannitol to the medium also improved the survival of the microplant Solanum tuberosum (Sarkar and Naik 1998) and several cultivars of Malus domestica (Kovalchuk et al. 2009). However, the addition of mannitol to the storage medium negatively affected the survival and multiplication capacity of microcuttings of Cedrus atlanticus and C. libani (Renau-Morata et al. 2006).

The presence of cytokinins in the medium could affect the stimulation of the cellular metabolism (cell division); on the other hand, during storage of the shoots, there was no root development. The presence of cytokinins is associated with the appearance of necrosis on explants during cold storage, but the lack of roots leads to a decrease in endogenous cytokinin biosynthesis and a consequent reduction in cell division (Bairu et al. 2009).

The influence of light intensity during storage has been studied for different species. The best results have been observed when storage was performed in darkness for Malus (Orlikowska 1992), Pistacia (Koç et al. 2014), Populus (Hausman et al. 1994), and Quercus (Romano and Martins-Loução 1999). Similar results were reported for $S$. macrophyllus where light affected negatively culture viability, multiplication rate and rooting response. Storage in low levels of illumination $\left(2-20 \mu \mathrm{mol} \mathrm{m} \mathrm{m}^{-2} \mathrm{~s}^{-1}\right)$ was reported for Fragaria (Reed 2002), Lilium (Bonnier and Van Tuyl 1997), Hosta (Gollagunta et al. 2005), and Solanum (Sarkar and Naik 1998). However, shoots of Castanea sativa were stored under the conditions of only $30 \%$ reduced illumination (Capuana and Di Lonardo 2013), but shoots of Podophyllum peltatum in a light level of approximately $52 \mu \mathrm{mol} \mathrm{m} \mathrm{m}^{-2} \mathrm{~s}^{-1}$ (Lata et al. 2010).

ABA is known as a growth retardant on in vitro growth. ABA treatment usually increases cold tolerance in stored plant material by increasing the expression of COR/LEA genes (Kobayashi et al. 2008) and accumulation of proline (Dörffling et al. 2009). A benefit for shoot survival is also displayed by ABA or/and proline pretreatment of Brassica campestris and B. napus (Wilen et al. 1994), and Begonia x erythrophylla (Burritt 2008). However, pretreatment of 
Fig. 6 The effect of carbohydrate treatment and light conditions ( $D$ darkness; $L$ light) on multiple shoots (a), \% rooting of shoots (b) and number of roots per shoot (c) of $S$. macrophyllus after storage at $10{ }^{\circ} \mathrm{C}$
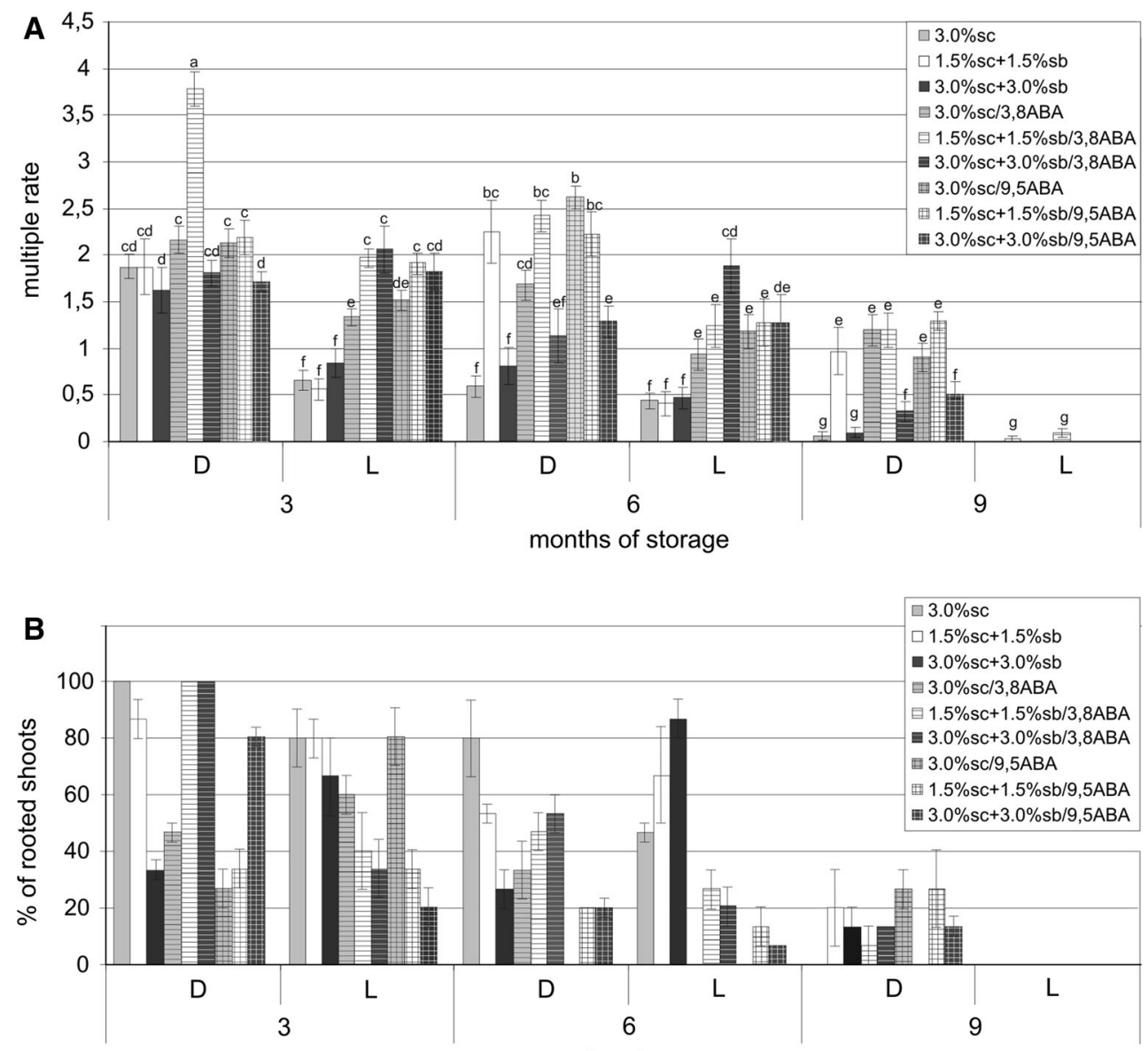

months of storage

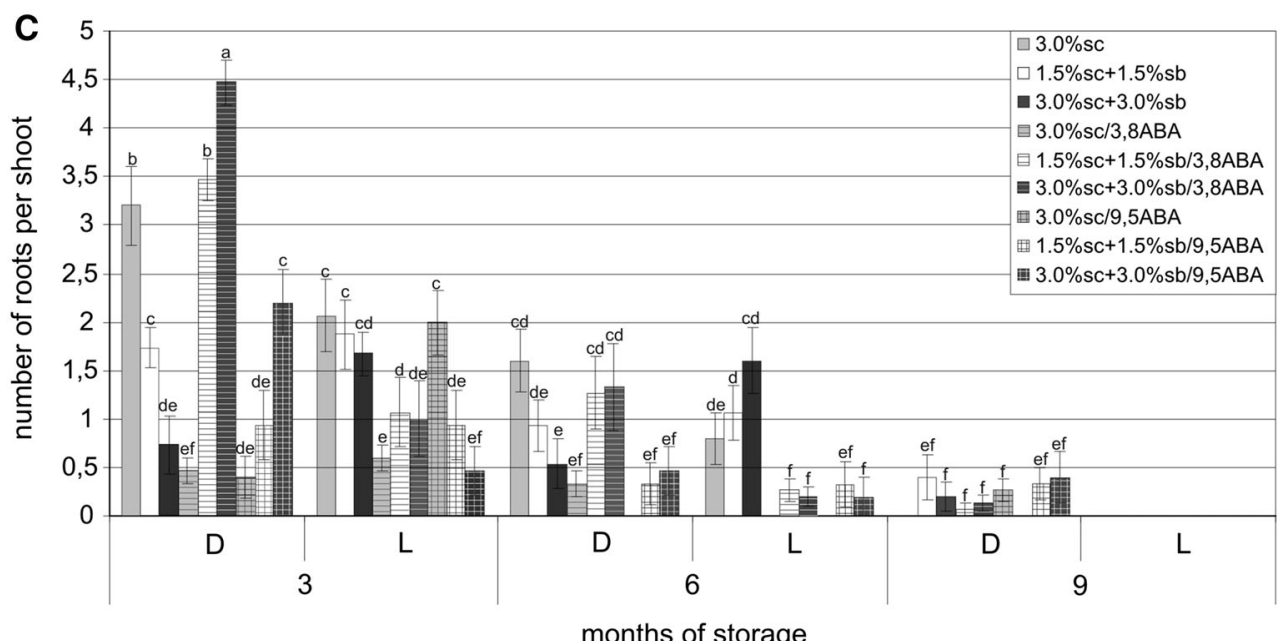

ABA did not influence the survival and multiple rate of shoots of Castanea sativa (Capuana and Di Lonardo 2013). In the case of $S$. macrophyllus the addition of ABA to storage medium stimulated survival and higher proliferation of shoots during regrowth in optimal conditions in comparison to shoots stored on a medium without ABA. However, the level of multiple rates was lower than for not-stored shoots, probably a long exposure to ABA strongly inhibited the effect of cytokinins.

To summarize, the results obtained demonstrated that $S$. macrophyllus shoot cultures can be stored effectively for up to 6 months without subcultures under a low temperature of $10{ }^{\circ} \mathrm{C}$, in darkness and using magenta boxes. The present study should be a step towards developing an 
alternative method for conserving $S$. macrophyllus genetic resources.

Author contribution statement Alina Trejgell designed and carried out the experiments, analysed the data and wrote the manuscript. Monika Kamińska carried out the experiments and helped in writing the manuscript. Andrzej Tretyn helped in preparing the manuscript.

Open Access This article is distributed under the terms of the Creative Commons Attribution 4.0 International License (http://crea tivecommons.org/licenses/by/4.0/), which permits unrestricted use, distribution, and reproduction in any medium, provided you give appropriate credit to the original author(s) and the source, provide a link to the Creative Commons license, and indicate if changes were made.

\section{References}

Bairu MW, Stirk WA, Van Staden J (2009) Factors contributing to in vitro shoot-tip necrosis and their physiological interactions. Plant Cell Tiss Org Cult 98:239-248

Bonnier FJM, Van Tuyl JM (1997) Long term in vitro storage of lily: effects of temperature and concentration of nutrients and sucrose. Plant Cell Tiss Org Cult 49:81-87

Burritt DJ (2008) Efficient cryopreservation of adventitious shoots of Begonia $x$ erythrophylla using encapsulation-dehydration requires pretreatment with both $\mathrm{ABA}$ and proline. Plant Cell Tiss Org Cult 95:209-215

Capuana M, Di Lonardo S (2013) In vitro conservation of chestnut (Castanea sativa) by slow growth. In Vitro Cell Dev Biol-Plant 49:605-610

Dörffling K, Dörffling H, Luck E (2009) Improved frost tolerance and winter hardiness in proline overaccumulating winter wheat mutants obtained by in vitro-selection is associated with increased carbohydrate, soluble protein and abscisic acid (ABA) levels. Euphytica 165:545-556

Gollagunta V, Adelberg JW, Rieck J, Rajapakse N (2005) Sucrose in storage media and cultivar affects post-storage regrowth of in vitro Hosta propagules. Plant Cell Tiss Org Cult 80:191-199

Grout BWW (1995) Low temperature storage of plant tissue cultures. In: Aiken-Christie $\mathbf{J}$ et al (eds) Automtion and environmental control in plant tissue culture. Kluwer, Dordrecht, pp 517-538

Hausman JF, Neys O, Kevers C, Gaspar T (1994) Effect of in vitro storage at $4{ }^{\circ} \mathrm{C}$ on survival and proliferation of poplar shoots. Plant Cell Tiss Org Cult 38:65-67

Kobayashi F, Takumi S, Nakamura C (2008) Increased freezing tolerance in an ABA-hypersensitive mutant of common wheat. J Plant Physiol 165:224-232

Koç İ, Akdemir H, Onay A, Çiftçi YÖ (2014) Cold-induced genetic instability in micropropagated Pistacia lentiscus L. plantlets. Acta Physiol Plant 36:2373-2384

Kovalchuk I, Lyudvikova Y, Volgina M, Reed BM (2009) Medium, container and genotype all influence in vitro cold storage of apple germplasm. Plant Cell Tiss Organ Cult 96:127-136

Lambardi M, Roncasaglia R, Previati A, De Carlo A, Dradi G, Da Re F, Calamai L (2006) In vitro slow growth storage of fruit rootstock inside gas-tight or gas-permeable containers. Acta Hort 725:483-488

Lata H, Moraes RM, Bertoni B, Pereira AMS (2010) In vitro germplasm conservation of Podophyllum peltatum L. under slow growth conditions. In Vitro Cell Dev Biol-Plant 46:22-27

Maryam A, Tariq R, Chuadhary S, Azmat R, Javed S, Khanam S (2014) A review: role of tissue culture (in vitro) techniques in the conservation of rare and endangered species. Pac J life Sci 2:93-103

Moges AD, Kara NS, Shibli RS (2003) Slow growth in vitro preservation of African Violet (Saintpaulia ionantha Wendl.). Adv Hort Sci 17:223-230

Murashige T, Skoog F (1962) A revised medium for rapid growth and bioassays with tobacco tissue cultures. Physiol Plant 15:437-497

Orlikowska T (1992) Effect of in vitro storage at $4^{\circ} \mathrm{C}$ on survival and proliferation of two apple rootstocks. Plant Cell Tiss Org Cult $31: 1-7$

Pruski K, Kozai T, Lewis T, Astatkie T, Nowak J (2000) Sucrose and light effect on in vitro cultures of potato, chokecherry and saskatoon berry during low temperature storage. Plant Cell Tiss Org Cult 63:215-221

Rao NK (2004) Plant genetic resources: advancing conservation and use through biotechnology. Afr J Biotechnol 3:136-145

Reed BM (1992) Cold storage of strawberries in vitro: a comparison of three storage system. Fruit Var J 46:98-102

Reed BM (2002) Photoperiod improves long-term survival of in vitrostored strawberry plantlets. HortScience 37:811-814

Reed BM, Sarasan V, Kane M, Bunn E, Pence VC (2011) Biodiversity conservation and conservation biotechnology tools. In Vitro Cell Dev Biol Plant 47:1-4

Renau-Morata B, Arrillaga I, Segura J (2006) In vitro storage of cedar shoot cultures under minimal growth conditions. Plant Cell Rep 25:636-642

Romano A, Martins-Loução MA (1999) In vitro cold storage of cork oak shoot cultures. Plant Cell Tiss Org Cult 59:155-157

Rybczyński JJ, Mikuła A (2006) Engagement of biotechnology in the protection of threatened plant species in Poland. Biodiv Res Conserv 3-4:361-368

Sarasan V (2010) Importance of in vitro technology to future conservation programmes worldwide. Kew Bull 65:549-554

Sarkar D, Naik PS (1998) Factors affecting minimal growth conservation of potato microplants in vitro. Euphytica 102:275-280

Shibli RS, Shatnawi MA, Subaih WS, Ajlouni MM (2006) In vitro conservation and cryopreservation of plant genetic resources: a review. World J Agric Sci 2:372-382

Trejgell A, Michalska M, Tretyn A (2010) Micropropagation of Senecio macrophyllus M. Bieb. Acta Biol Crac 52:67-74

Wilen RW, Gusta LV, Lei B, Abrams SR, Ewan BE (1994) Affects of abscisic acid (ABA) and ABA analogs on freezing tolerance, low-temperature growth, and flowering in rapeseed. J Plant Growth Regul 13:235-241

Withers LA, Engelmann (1997) In vitro conservation of plant genetic resources. In: Altman A (ed) Biotechnology in agriculture. Marcel Dekker, New York, pp 57-88

Zarzycki K, Szeląg Z (2006) Red list of the vascular plants in Poland. In: Mirek Z (ed) Red list of plants and fungi in Poland. W. Szafer Institute of Botany Polish Academy of Sciences, Kraków, pp 9-20 